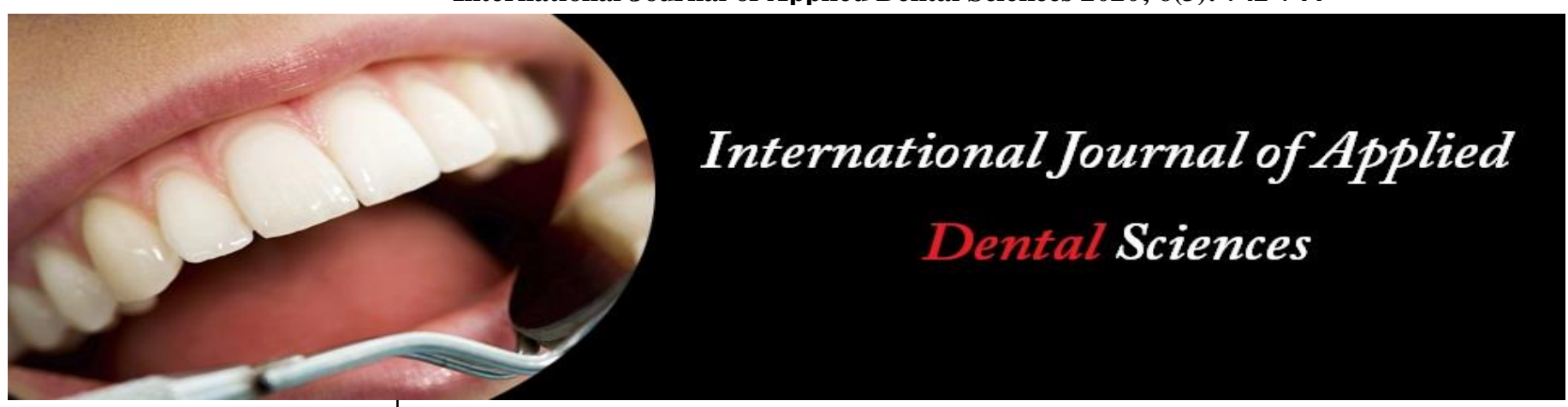

ISSN Print: 2394-7489

ISSN Online: 2394-7497

IJADS 2020; 6(3): 742-744

(C) 2020 IJ ADS

www.oraljournal.com

Received: 13-05-2020

Accepted: 15-06-2020

Dr. Farnaz Yasmin Shah MDS (Oral and Maxillofacia Pathology), Consultant Oral Pathologist, Guwahati.

Gandhibasti, Assam, India

Dr. Preety Sehrawat

MDS (Oral and Maxillofacial

Pathology), Consultant Oral

Pathologist and Dental Surgeon.

Physiodent - Dental and

Wellness clinic, Som Bazar

Chowk Najafgarh, New Delhi,

India

Dr. Arshad Bin Hussain

MDS (Periodontology), Reader,

Regional Dental College,

Bhangagarh, Guwahati, Assam,

India
Corresponding Author: Dr. Farnaz Yasmin Shah MDS (Oral and Maxillofacial Pathology), Consultant Oral Pathologist, Guwahati,

Gandhibasti, Assam, India

\section{Smoking and its ramifications relating to oral mucosa}

\author{
Dr. Farnaz Yasmin Shah, Dr. Preety Sehrawat and Dr. Arshad Bin \\ Hussain
}

DOI: https://doi.org/10.22271/oral.2020.v6.i3k.1030

\section{Abstract}

Smoking has adverse effects in oral health. In today's day to day life smoking has become a common practice which eventually damages the hard and soft tissues of the oral cavity. Along with periodontal diseases, surface epithelial changes, smoking also increases the risk of oral precancer and oral cancer with various other plausible effects. Oral Health Professionals plays a pivotal role in screening and creating awareness in the prevention and diagnosis of such diseases. Therefore this review focuses on the effects of smoking, components of burning tobacco that could affect the overall oral health and the benefits of ceasing the habit of smoking.

Keywords: Oral health, cigarette smoking, tobacco

\section{Introduction}

Oral cavity is a speculum to the existing health conditions of a person. Time and again such diseases and conditions are unobserved because of the laxity and unawareness of the individuals. Among health professionals, oral pathologists have a substantial role in discerning and correlating the role of smoking and oral diseases. The role of smoking can be directly or indirectly linked to various oral, peri-oral diseases and other plausible effects of the oral environment. The oral effects of smoking can range from periodontal diseases to surface pigmentations such as smoker's palate, smoker's melanosis and other possible effects such as salivary changes, dental caries, altered taste and smell. It can also results in oral precancer and cancer. Various chemical components of the burning tobacco could cause perilous conditions of the oral environment and smoke of these components could affect the hard and soft tissues of the oral cavity in distinct manners.

\section{Oral precancer}

Oral leukoplakia is a white patch on the oral mucosa that can neither be scraped off nor classified as any other diagnosable lesion ${ }^{[1,2]}$.

It may vary in appearance that may range from a smooth, slightly translucent, white area to an area which is thickened, hardened and the lesion can eventually appear fissured. Leukoplakia in smokers usually involves buccal mucosa and depending on the frequency it could be a generalized diffuse lesion or a localized lesion involving less area ${ }^{[3,4]}$.

It is seen that $2-6 \%$ of oral leukoplakia can mutate into a malignancy ${ }^{[1]}$. Y. S. Yildrium et al. in their study found that smokers have altered pigmentation in the oral mucosa. They studied the colour changes in smokers by RGB (Red Green Blue) photographic evaluation of the oral mucosa. They have found that the total RGB values of the oral mucosa in smokers were lower which in turn suggests that the continuous use of tobacco darkens the oral mucosa ${ }^{5}$. Many studies have also shown that post-cessation of tobacco consumption can leads to decrease incidence of oral leukoplakia ${ }^{[6]}$.

\section{Oral cancer}

Past studies revealed that smokers have an increase risk of developing carcinoma of the mouth, oesophagus, pharynx in comparison to non smokers $[7,8,9,10]$.

Many carcinogens present in cigarette such as tar, carbon monoxide, benzopyrene are present 
along with nicotine. An important metabolite of nicotine called cotinine can be detected in urine sample, blood sample and gingival fluid of smokers ${ }^{[11]}$. This sample testing can be helpful in ruling out the frequency of smoking which in turn could aid in diagnosis of the oral carcinomatous changes. In the early stages, oral cancer is usually painless, appear bright red. Surface can be granular or smooth, usually without ulceration and induration ${ }^{[12]} .52 \%$ of oral cancer cases have five survival rate ${ }^{[7]}$. Cessation of smoking can increase chances of survival rate in oral cancer patients ${ }^{[1]}$.

\section{Periodontal disease}

Smoking could cause a significant drop in $\operatorname{IgA}$ and $\operatorname{IgG}$ secretion level which could suppress the defence mechanism of the body ${ }^{5}$.It is seen that nicotine of the smokers could interfere with the binding capacity, proliferative nature of the cells of periodontal ligaments. It could also enhance colonization of periodontal pathogens ${ }^{[13,}{ }^{14]}$.Various Periodontal problems such as increase in depth of pocket, loss of alveolar bone, motility of tooth are more frequently seen in smokers ${ }^{1}$. It has been found by researchers that smoking could cause diminution in oral leukocyte activity which in turn suppresses the body's immune responses ${ }^{\mathbf{1 5}}$. Improvement in the advancement of the periodontal diseases was seen evidently after the cessation of smoking ${ }^{[1]}$.

\section{Acute necrotizing ulcerative gingivitis (ANUG)}

It is a condition which is characterized by bleeding, painful, necrotic, ulcerative gingiva. It is seen that in heavy smokers, the incidence of ANUG is higher. Other factors that could contribute to this could be mental agony, poor oral hygiene etc. [1]. Smoking can impair the humoral, cellular, inflammatory and vascular response which could aid in advancement of this condition ${ }^{[16]}$.

\section{Halitosis and staining of teeth}

Smoking and halitosis are parallel as smokers are seen to have malodour. It has been found that the volatile sulphur compound present in tobacco promotes malodour. Studies have found that periodontal diseases and decrease salivation due to smoking were also contributory factors of halitosis ${ }^{[17}$, $18]$

Staining of teeth could be a result of the burned tobacco component especially Tar which could cause discoloration of tooth in the cervical region and lingual surfaces of anterior teeth ${ }^{[1]}$.

\section{Dental calculus and plaque}

Smokers are seen to have direct relationship in building up of calculus. Increase smoking leads to increase accumulation of calculus $^{19}$. Studies have shown that smokers develop more dental plaque than non-smokers.

\section{Other oral diseases due to surface epithelial changes Stomatitis nicotina (Smoker's palate) and Smoker's melanosis}

It is a condition that could be characterized by wide area of keratosis on the palate, the area is represented as elevated nodules which are white in colour and appear like a cobblestone.

This condition mainly occurs in reverse smoking habit, cigar and pipe smokers. The relation of smoking to this condition could be directly linked to the heat and persistent irritation cause by smoking in the palatal vault ${ }^{[20]}$.

\section{Other possible effects of tobacco smoking}

\section{Salivary changes}

Studies have found that cigarette smokers have higher levels of thiocyanate which is found in increased amount in their saliva and could be used to monitor the status of the habit ${ }^{[2]}$. Studies have shown that smokers have lower cystatin levels in saliva which acts as an inhibitory factor for ceratin enzymes which are proteolytic in nature ${ }^{[21]}$.

\section{Dental Caries}

Increased incidence of dental caries have been seen in smokers. Fewer studies have shown a relationship between caries and smoking as the microbial count of Streptococcus mutans and Lactobacillus were found higher in smokers ${ }^{[22,}$ 23].

\section{Taste and smell}

Various studies have shown that smoking caused altered olfaction and taste due to the damage in the receptors of olfactory cells and taste buds. Acuity of taste and smell had an inverse relationship to the dose of smoking ${ }^{[2]}$. Studies have also pointed out that increase nicotine decreases the consumption of sweet food and vice versa ${ }^{[1]}$. Smokers after ceasing their habit had more appetite for sugar ${ }^{[24]}$. Stoppage of the habit in this way resulted in better olfaction and taste.

\section{Conclusion}

Tobacco smoking is seen to cause various oral diseases and conditions which could alter a person's lifestyle and increase morbidity. Therefore by conducting further research studies, knowledge on their dose, frequency, effects could be illustrated well. Dental clinicians and researchers play an important role in the intervention of such diseases and conditions as they deal with the screening of oral environment. Damage to oral environment can be prevented by cessation of smoking and monitoring tobacco levels of individual smokers. Thus with the help of weighty evidences oral health professionals could emphasize on curtailing this habit by educating, monitoring and being a part of Tobacco Intervention programme and policies.

\section{References}

1. Christen AG. The Impact of Tobacco Use and Cessation on Oral and Dental Diseases and Conditions. The American Journal of Medicine 1992;93:25-31

2. Christen AG, McDonald JL, JR, Christen JA. The impact of tobacco use and cessation on non-malignant and precancerous oral and dental diseases and conditions. Indianapolis, Indiana: Indiana University School of Dentistry 1991, 1-73.

3. Baric JM, Alman JE, Feldman RS, Cauncey HH. Influence of cigarette, pipe and cigar smoking, removable partial dentures, and age on oral leukoplakia. Oral Sung Oral Med, Oral Pathol 1982;54:424-9.

4. Bouquot JE, Weiland L, Ballard D, Kurland L. Leukoplakia of the mouth and pharynx in Rochester, MN 1935-1984; incidence, clinical features and follow-up of 463 patients from a relatively unbiased patient pool [Abstract 441. American Academy of Oral Pathology Meebng, Philadelphia, Pennsylvania 1988, 8-12.

5. Yildirim YS, Degirmenci N, Tugrul S, Ozturan O. Effects of Smoking on healthy oral mucosa: a red-greenblue (photographic) evaluation. B-ENT 2017;13:9-13, 2017;13:10-29

6. Reibel J. Tobacco and Oral Diseases. Med Princ Pract 2003; 12 :22-32, 2003;12:22-32.

7. American Cancer Society. Cancer facts and figures 1991, Atlanta, Georgia: American Cancer Society 1991;5(11):19-20. 
8. Christen AG, McDonald JL, Jr, Klein JA, Chnsten JA, Guba CJ. A Smoking cessation program for the dental office. Indianapolis, Indiana. Indiana University School of Dentistry 1990, 5-10.

9. U.S. Department of Health and Human Services, The health consequences of using smokeless tobacco: a report of the advisory committee to the surgeon general 1986, 1195.

10. Silverman S, Jr. Oral cancer 1981, 1-124.

11. Ozturka O, Fidancib I, Unalc M. Effects of smoking on oral cavity. J. Exp. Clin. Med 2017;34:3-7.

12. Mashberg A, Samit A. Early diagnosis of asymptomatic oral and oropharyngeal squamous cancers. CA Cancer J Clin 1995;45:328-351.

13. Blackwell CC, Tzanakaki G, Kremastinou J. Factors affecting carriage of Neisseria meningitidis among Greek military recruits. Epidemiol Infect 1992;108:441-448.

14. Grossi SG, Skrepcinski FB, DeCaro T, Zambon JJ, Cummins D, Genco RJ. Response to periodontal therapy in diabetics and smokers. J Periodontol 1996;67:10941102.

15. Clarke NG, Care SE. Etiology of chronic periodontal disease: an alternative perspective. J Am Dent Assoc 1985;110:689-91.

16. Kinane DF, Bartold PM. Clinical relevance of the host responses of periodontitis. Periodontol 2000, 2007;43:278-293.

17. Al-Atrooshi BA, Al-Rawi AS. Oral halitosis and oral hygiene practices among dental students. J. Bagh. Coll. Dent 2007;19:72-76.

18. Scully C, Greenman J. Halitology (breath odour: aetiopathogenesis and manage-ment). Oral Dis 2012;18:333-345.

19. Ainamo J. The seeming effect of tobacco consumption on the occurrence of periodontal disease and dental caries, Suomen Hammaslaak Arilehti 1971;67:87-94.

20. Bhashkar SN. Oral lesions in the aged population. A survey of 785 cases, Geriatrics 1986;23:137-49.

21. Lie MA, Loos BG, Henskens YM, Timmerman MF, Veerman EC, van der Velden U, et al. Salivary cystatin activity and cystatin $\mathrm{C}$ in natural and experimental gingivitis in smokers and non-smokers. J Clin Periodontol 2001;28:979-984.

22. Sakki T, Knuuttila M. Controlled study of the association of smoking with lactobacilli, mutans streptococci and yeasts in saliva. Eur J Oral Sci 1996;104:619-622.

23. Huang R, Li M, Gergory RL. Effect of nicotine on growth and metabolism of Streptocuccus mutans. Eur J Oral Sci 2012;120:319-325.

24. Rodin J. Weight change following smoking cessation: the role of food intake and exercise. Addict Behav 1987;12:303-17. 